\title{
Deviations from Lithostatic Pressure during Metamorphism: fact or fiction?
}

\section{Report}

\section{Author(s):}

Tajčmanová, Lucie

Publication date:

2016

Permanent link:

https://doi.org/10.3929/ethz-a-010657624

Rights / license:

In Copyright - Non-Commercial Use Permitted

Funding acknowledgement:

335577 - Interplay between metamorphism and deformation in the Earth's lithosphere (EC) 


\title{
Deviations from Lithostatic Pressure during Metamorphism: fact or fiction? TAJČMANOVÁ L.
}

\author{
Department of Earth Sciences, ETH Zurich, Switzerland
}

Estimation of pressure-temperature $(P-T)$ from petrographic observations on metamorphic rocks has become a common constituent of petrology studies during the last 50 years (e.g. Perchuk, 1968). Pressure plays an important role in the interpretation of tectonic processes because it is traditionally converted to depth via the lithostatic pressure formula $(P=\rho g h)$. This data then serves as a key input in geodynamic reconstructions and thus directly influence our understanding of lithospheric processes. Such an approach might have led the metamorphic geology field to a certain level of stagnation.

Even though the deviations from lithostatic pressure have already been documented by several studies in the past (e.g. Jamieson, 1963; Petrini \& Podladchikov, 2000; Mancktelow, 2008), this topic is still controversial, attracting more attention recently. This is due, in part, to an increasing number of studies in which directly-measured pressure variations are reported (e.g. Enami et al., 2007; Chen et al., 2015), but also to recent advances in equilibrium modelling under pressure gradients (Tajčmanová et al., 2014; 2015; Vrijmoed \& Podladchikov; 2015) and in geodynamic reconstructions (e.g. Li et al., 2010; Schmalholz \& Podladchikov; 2013). Considering the mechanically-maintained deviations from lithostatic pressure seems to be critical for a correct interpretation of microstructural observations in metamorphic rocks as well as for quantification of the processes on a large (metre and above) scale. Therefore, this topic is timely and important because ignoring pressure variations in petrological analysis may significantly influence our understanding of the processes in the Earth's interior. Still, there 
might be doubts about whether pressure variations can be maintained at geological time-scale (Ma); how to recognize pressure variations in samples; what the magnitude of the deviation from the lithostatic pressure is, and how such deviations can influence the metamorphic $P-T$ paths. This Special Issue, involving new views of metamorphic processes, can thus serve as an inspiration for future research opening new ways of looking at metamorphic rocks. Hopefully, this will help to reinvigorate metamorphic geology.

The Special Issue comprises five invited papers from the EGU 2014 session held in Vienna, Austria, convened by Lucie Tajčmanová (ETH Zurich), Holger Stunitz (University of Tromsø), Ralf Milke (Free University of Berlin) and James Connolly (ETH Zurich). Two additional papers were involved in the Special Issue based on the open call advertised on the GEOMETAMORPHISM, GEO-TECTONICS and MSA-Talk email groups. The purpose of the Special Issue is to review the role of pressure in quantification approaches in petrology with particular reference to the interpretations of the crustal and orogenic processes. The Issue gathers papers which would cover the following topics: 1) classical diffusion-controlled systems vs. systems with pressure variations on a grain-scale, accompanied by appropriate quantification approaches, 2) how and when pressure variations can be maintained at geological timescales, 3) lithostatic vs. non-lithostatic pressure in the field and in geodynamic reconstructions.

The first, introductory, paper of Taras Gerya presents an overview of various aspects of tectonic over-pressure and under-pressure in relation to petrologically-relevant lithospheric processes. The paper provides arguments why the lithostatic pressure concept is the most preferred one and what effect the deviations from lithostatic pressure can have on metamorphic $P-T$ paths. Furthermore, the recent advances in numerical models of lithospheric tectonics are discussed with respect to non-lithostatic pressure. 


\section{Grain-scale observations and quantification approaches}

The most commonly documented pressure variations are from the grain-scale where they can be even directly measured by spectroscopic methods (e.g. Enami et al., 2007). However, direct measurements are not feasible for more complex rock microstructures. Thus, to determine whether the microstructure was mechanically-controlled with preserved pressure variations or diffusion-controlled still remains hard to establish. Furthermore, in case of microstructures involving pressure heterogeneities, what approaches can be used to determine the magnitude of the pressure deviations? The following four papers tackle these questions from both, the lithostatic and non-lithostatic, views.

Angel et al. provide a quantification of the deviation from lithostatic pressure on a spherical inclusion in an elastically isotropic host. Their model involves a concept of the thermodynamic isomeke to determine the over- or under-pressure developed in the inclusion at various $P$ and $T$ conditions. The isomeke approach is then used to calculate the elastic interaction between the host and inclusion which allows inferring the final pressure of the inclusion. The estimated deviations from lithostatic pressure are thus maximum deviations from the elastic behaviour.

On the contrary, the contribution of Zhukov \& Korsakov presents a visco-elastic model for a coesite-garnet, aragonite-garnet and diamond-garnet host-inclusion systems in order to get $P-$ $T-t$ paths from residual pressure patterns considering the kinetics of phase change reactions. Following the classical view of metamorphic rocks assuming fast viscous relaxation, their model predicts very high exhumation rates from depths $>90 \mathrm{~km}$ or short residence time at ultrahighpressure (UHP) conditions. 
Mechanically-maintained pressure variation leads to a chemical zoning in solid solutions or can influence the crystallization of phases corresponding to the mechanically-induced pressure gradient. The two following papers provide examples of how to examine possible pressure variation directly in petrographic observations. As shown in the paper of Angel et al. and Zhukov \& Korsakov, garnet is a typical representative of a strong host that can maintain the pressure variations. Axler \& Ague document halos of rutile \pm apatite needles and plates around quartz or multiphase inclusions in garnet from two localities - the ultra-high-temperature (UHT) gneiss from Central Maine Terrane in northeastern Connecticut (USA) and UHP diamondiferous saidenbachite from the Saxonian Erzgebirge (Germany). They suggest a model where inclusions impose a stress on the host garnet by volume change or retention of their entrapment pressure. Such a stress perturbation leads to the development of dislocations and other defects in the host that created nucleation sites and thus catalyzed the process of rutile and apatite precipitation.

The petrology approaches currently provide tools for quantification of both—mechanicallyand diffusion-controlled-microstructures. Therefore, it is only a question of how and when the particular tool is the most appropriate to use. The paper of Moulas et al. illustrates a possible way to distinguish between mechanically- and diffusion-controlled microstructure. They discuss the applicability of the unconventional barometry on a retrogressed eclogite sample from Rhodope (Greece) with similar microstructures to those in which the unconventional barometry of Tajčmanová et al. (2014) was originally applied. The Rhodope sample shows diffusion patterns along the grain boundaries which rules out the application of unconventional barometry. Therefore, an improved two-dimensional numerical model with coupled reaction and chemical diffusion along the grain boundaries was developed to explain the diffusion-controlled microstructure. 


\section{Scale-independent preservation of the pressure variation}

One of the reasons why the presence of pressure variations has been neglected for such a long time is the common idea of fast pressure relaxation in rocks. Rocks are heterogeneous and undergo processes like deformation or fluid infiltration and melting which are believed to enhance the viscous relaxation as, for example, assumed in Zhukov \& Korsakov paper. However, this hypothesis has not been rigorously quantified before.

The work of Dabrowski et al. is focused on determining the time-scale of pressure variation preservation. Naturally, the pressure gradients tend to be viscously relaxed with time. However, how long it would take to relax the pressure heterogeneity depends on the rheology properties of the material. The common linear viscous models might be inappropriate for application to rocks. Therefore, the authors compare viscous relaxation in Newtonian and non-Newtonian (powerlaw creep) rheology environments. It is shown that the viscous relaxation in the non-Newtonian material depends significantly on the power-law creep exponent. For larger power-law exponents, the pressure variation can be maintained on geology-relevant timescales (Ma). Their model is scale-independent.

\section{Large scale observations and numerical modelling}

As mentioned in the Gerya's contribution, there are still challenges connected with explaining (U)HP metamorphism particularly in the Alps. Therefore, the last two papers are dedicated to this region. The paper of Schenker et al. focuses on the Pennine domain of the Central and Western Alps. The authors provide a unique review of structural, petrological and geochronological data from Dora-Maira, Monte Rosa, Gran Paradiso, Adula/Cima Lunga nappes 
and the Zermatt-Saas Zone in the context of deviations from lithostatic pressure. Furthermore, they evaluate the current exhumation models in detail and point out the inconsistencies of these models with respect to the field observations. Finally, they suggest that an orogenic wedge model involving dynamic stresses deviating from the lithostatic pressure would better explain the structural and petrographic observations.

In connection to the field-related paper of Schenker et al., Schmalholz \& Duretz present an alternative two-dimensional thermo-mechanical numerical model of nappe formation by tectonic compression. The authors show how metamorphism in the nappes can be affected by differential stress due to compression as well as the local temperature increase due to heat dissipated in deforming shear zones. They emphasize the importance of shear heating for crustal shear zones and point out the difficulties in identifying temperature gradients connected with shear heating in the field. Additionally, the decay of the stress and temperature variation on the crustal scale is discussed.

\section{ACKNOWLEDGEMENTS}

I would like to thank the editors of JMG for giving me the opportunity to create this Special Issue and especially to D. Robinson for being patient with me as a guest editor and for the invaluable editorial help he provided. This Issue would not be possible without the authors of the contributions, so my big thank-you goes to them. I also acknowledge the careful and constructive work of all the reviewers. The idea to make this Special Issue came out of the research done within the ERC grant MADE-IN-EARTH n. 335577 which I sincerely acknowledge. 


\section{REFERENCES}

Chen, K. C., Kunz, M., Tamura, N. \& Wenk, H-R., 2015. Residual stress preserved in quartz from the San Andreas Fault Observatory at Depth. Geology, 43, 219-222.

Enami, M., Nishiyama, T. \& Mouri, T., 2007. Laser Raman microspectrometry of metamorphic quartz: A simple method for comparison of metamorphic pressures, American Mineralogist, 92, 1303-1315.

Jamieson, J.C., 1963. Possible occurrence of exceedingly high pressures in geological materials. Geological Society of America Bulletin, 74, 1067-1070.

Li, Z.H., Gerya, T.V. \& Burg, J.P., 2010. Influence of tectonic overpressure on P-T paths of HPUHP rocks in continental collision zones: thermomechanical modelling. Journal of Metamorphic Geology, 28, 227-247.

Mancktelow, N.S., 2008. Tectonic pressure: Theoretical concepts and modelled examples. Lithos, 103, 149-177.

Perchuk, L.L., 1968. Pyroxene-garnet equilibrium and the depth facies of eclogites, International Geology Reviews, 10, 280-318.

Petrini, K. \& Podladchikov, Y., 2000. Lithospheric pressure-depth relationship in compressive regions of thickened crust. Journal of Metamorphic Geology, 18, 67-77.

Schmalholz, S.M. \& Podladchikov, Y.Y., 2013. Tectonic overpressure in weak crustal-scale shear zones and implications for the exhumation of high-pressure rocks. Geophysical Research Letters, 40, 1984-1988.

Tajčmanová, L., Podladchikov, Y., Powell, R., Moulas, E., Vrijmoed, J.C. \& Connolly, J.A.D., 2014. Grain-scale pressure variations and chemical equilibrium in high-grade 
metamorphic rocks. Journal of Metamorphic Geology, 32, 195-207.

Tajčmanová, L., Vrijmoed, J. \& Moulas, E., 2015. Grain-scale pressure variations in metamorphic rocks: implications for the interpretation of petrographic observations. Lithos, 216-217, 338-351.

Vrijmoed, J. C. \& Podladchikov, Y. Y., 2015. Thermodynamic equilibrium at heterogeneous pressure. Contributions to Mineralogy and Petrology, DOI 10.1007/s00410-015-1156-1. 